\title{
Development of the industrial sector in the regions through innovation
}

\author{
Oleg Goycher ${ }^{1}$, Olga Bugrova ${ }^{1, *}$, and Roman Kudryakov ${ }^{1}$ \\ ${ }^{1}$ Vladimir State University named after Alexander and Nikolai Stoletovs, 600005, Gorkogo str, 79, \\ Vladimir, Russia
}

\begin{abstract}
The purpose of the study is to consider the development level of innovative perspective based on prioritization, putting in the first place the industrial sector as the quintessence of all activities in the region. Innovative transformations are an integral part of the strategy implementation for the development of the economy of the Russian Federation in general and regional strategies in particular. At the same time, each of the participants in innovation activities seeks to save them, which leads to the search for less resource-intensive or alternative technologies, to consider the possibility of using elements of outsourcing or engaging regional authorities in the implementation. In most cases, when forming views on innovation processes, the sectoral complex as a whole is considered, which does not take into account the peculiarities of the functioning of individual sectors. The results of the study can be useful for meeting the conditions of the compliance of the goals and objectives of the region's innovative development, the common vision of project investment, the dynamics of the industrial sector development will be met, and the foundations for the further projection of the proposed tools to manage the economies of the regions and the country.
\end{abstract}

\section{Introduction}

An exit on the innovative way corresponds to the development strategy of the Russian Federation [1] and presupposes the presence of tools in the territorial subject or a certain area, which contribute to more effective implementation and realization of the existing potential. It is the innovations implementation that allows achieving the following key advantages:

- to ensure the possibility of creating goods, services and technologies with characteristics that meet both the needs of end users and the main trends of technological progress;

- to create a set of competitive advantages for the participants of the innovation process, which will allow to switch to import substitution by organizing the production of the necessary products at existing production areas;

- to achieve the growth of socio-economic indicators of development of both the subjects and the country, which, in turn, will have a positive effect on the social standard of living.

\footnotetext{
*Corresponding author: olga sergeevna89@inbox.ru, oleg.goiher@yandex.ru
} 
Thus, the main task of the authorities in this direction should be to create conditions for the realization of the innovative potential of enterprises, to assist in the implementation of this process in terms of organizing information, legal, consulting, financial or other support [2-3].

The works of such authors as S.Y. Glazyev, A.G. Granberg, L.V. Kantorovich, Y.P. Morozov, etc. were devoted to the study and development of the regional economy.

Contributions to the development and use of innovations in the region relate to the works of such scientists as: I.M. Bortnik, O.G. Golichenko, E.B. Lenchuk, L.E. Mindeli, etc.

\section{Methods}

The following methods were used in this study:

- analysis of statistical information, which was an interpretation of information from statistical collections;

- graphical method, in the framework of which the mechanism and model were built, which allowed the author to visually present his vision of the process of interaction between the subjects of the innovation sector of the industrial sector, as well as the elements of their financing;

- economic and mathematical modeling expressed in the construction of mathematical interpretations of the constructed model;

- systematic approach expressed in considering the totality of interacting entities of the industrial sector of the territory.

\section{Results}

Innovative activity in the context of the spheres of the country's economy has various dynamics indicators, while it is the industrial sector that has the greatest development potential.

In terms of the volume of domestic research and development costs, by the end of 2016, the largest share in the amount of $28 \%$ falls on the industrial production sector [4], which is clearly shown in Figure 1.

It should be noted separately that among the areas of industrial production, the largest amount of funds was directed to the production of automobiles and vehicles, increasing the economic efficiency and technological level of industrial production, as well as the production of devices, and the smallest - to the production of clothing, textiles and leather products, food products and drinks.

In terms of considering the volume of produced innovative goods, works and services, by the end of $2016,8.4 \%$ of the total number of them were shipped in the industrial production sector. For comparison, the value of this indicator in the construction sector was only $1.7 \%$, and in the service sector $11.9 \%$ [4].

The industrial sector, being a part of the regional economy, is subject to all the trends that are characteristic of territorial systems, i.e. the industry is dependent on consumer preferences, resource support, the degree of government influence, competitive position, etc. 


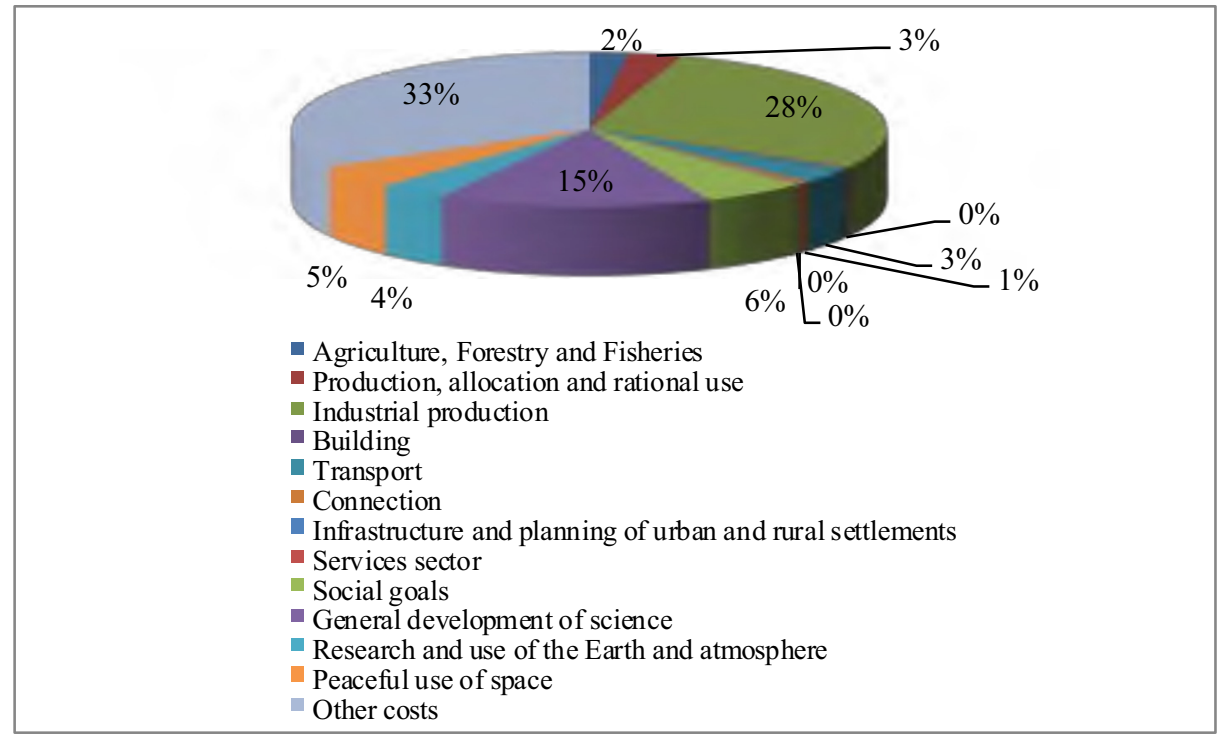

Fig. 1. Structure of domestic expenditures on research and development in socio-economic goals, \%.

The development of the industrial sector [5-7] of the region in terms of the implementation of the innovative way of implementing its strategy is presented in Figure 2.

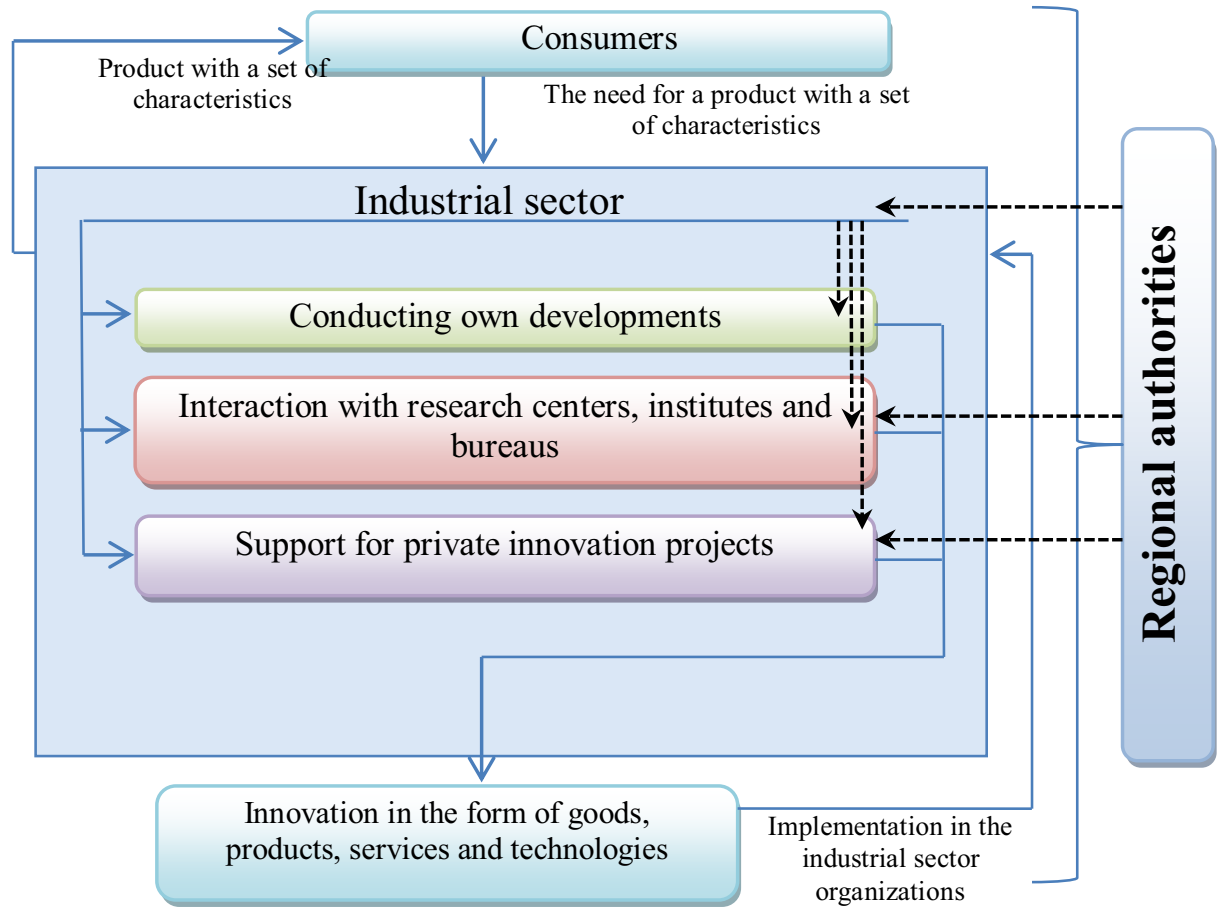

Fig. 2. Mechanism of the industrial sector development in the region.

Considering in more detail the proposed mechanism, it should be noted that the industrial sector is directly dependent on consumer requests, thereby following the results of analytical studies of the segment, profitability dynamics or trends in scientific and 
technological progress, enterprises of the sector "make out" for themselves a request for a product, i.e. consumers actually dictate requirements for the sector, objectively or subjectively changing their social and consumer standard. On the basis of the evolutionary view of the development of socio-economic systems, it can be argued that the "requested" product will have a new (in most cases), more advanced set of characteristics, which will cause the industrial sector to respond, creating new product, production technology, application technology, etc. [8]

To solve such problems, companies in the sector have three main options:

1. Carrying out own developments [9] - at the majority of enterprises in the industrial sector, there are research and development units in the structure, which, in its turn, has several advantages:

- the possibility of constant advancing progress, starting from the development strategy at a particular stage of market transformations;

- the creation of prerequisites for their own impact on the consumer, independently forming his "requests";

- reduction of costs due to the formation of innovations, taking into account its own resource capabilities, etc.

2. Interaction with research organizations - the next opportunity to respond to the situation may be an appeal to third-party research centers (specialized, located in the structures of universities, venture capital companies, etc.). This approach has its own set of advantages:

The issue of financing deserves special attention, such as at various stages of the proposed mechanism various technologies for generating sources of cash flows of process participants are provided, then we can talk about creating a separate investment project with each set of properties for each "request". Financial support will require not only the processes of technical implementation of innovation, but also the introduction into the market, bringing the product to the form of goods. Such sources of cash flows formation process are becoming most relevant, in which the system of grant support can play a significant role. Thus, the authorities systematize the work of the industrial sector, financing those innovative projects [10-12], which possess a set of the most socially significant indicators for the region, neutralizing market imbalances, and activating growth points.

In future, we will clarify the procedure for project financing of innovative activities of the industrial sector. First of all, we will form a visual model in the form of a system configurator, which is presented in Figure 3. 


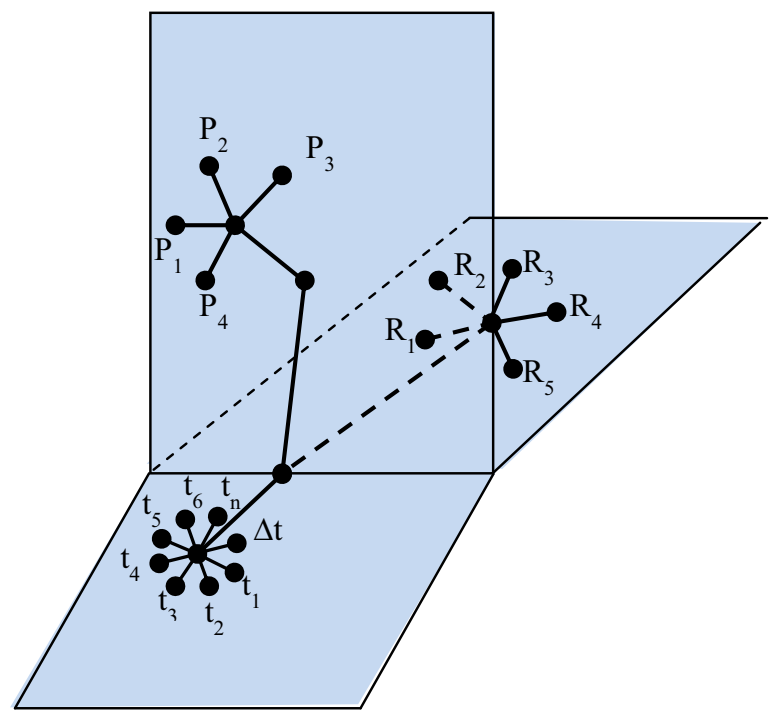

Fig. 3. Model of project financing of innovation in the industrial sector.

In the presented configurator, three interrelated systems act as planes: projects $(\mathrm{P})$, resources $(\mathrm{R})$, and time $(\mathrm{t})$.

All projects implemented in this sector are most often classified due to three main reasons:

1. For different types of projects, it takes different time and all kinds of resources;

2. Participation by regional authorities for different types is not always the same;

3. The number of projects varies by type, therefore, when analyzing the development of the sector as a whole, it is necessary to take into account the specifics of their implementation.

The mathematical interpretation of the project plane, which is the totality of all projects implemented by the sector, can be presented in the following form (1):

$$
\sum P=P 1+P 2+P 3+P 4 \rightarrow o p t
$$

P1 - small projects;

P2 - medium projects;

P3 - large projects;

P4 - megaprojects.

Providing all kinds of resources is an integral part of the project financing of innovation in the industrial sector. A specific feature of this element is the need for a congruent approach to ensuring this process from both the region and the object and the subject of investment, which in general can be represented (2):

$$
\sum R=R 1+R 2+R 3+R 4+R 5 \rightarrow o p t
$$

R1 - human resources;

R2 - financial resources;

$\mathrm{R} 3$ - information resources;

R4 - intellectual resources;

R5 - material resources.

Time is a kind of resource, non-renewable and irreplaceable, requiring special attention and constant monitoring, because the speed of implementation of a particular idea or technology into real life is the basis for both the survival of an individual participant in the 
industrial sector and the competitiveness of the industry as a whole. The mathematical interpretation of the time plane can be represented in the following form (3):

$$
\sum t=t 1+t 2+t 3+t 4+t 5+t 6+t 7+t n+\Delta t \rightarrow o p t
$$

t1 - time spent on obtaining information;

t2 - time spent on information processing;

$\mathrm{t} 3$ - time spent on possible consultations;

t4 - time spent on the conclusion;

t5 - time spent on correcting comments (by the investor);

t6 - time spent on making management decisions for the practical implementation of the project;

t7 - time spent on searching for information;

tn - time required to complete each phase of the project;

$\Delta \mathrm{t}$ - error, possible non-traditional projects requiring the involvement of outside experts, etc.

Managing the time resource should be reduced to the development of criteria for optimal time expenditure [13] at each stage of the innovation project implementation. It should be noted separately that the aspiration of $\sum \mathrm{t}$ should not be to $\mathrm{min}$, but to opt, since minimization creates additional barriers in the processing of information and in the implementation of each stage of the process.

The intersection of the planes and the formation of perpendiculars of each of the three systems is aimed at determining the optimal point characterizing the most efficient use of project investment types, their resource and time support, that is, the ideal state of the model under consideration [14-15].

\section{Discussion}

It should be noted that the presented mechanism and configurator are generalized and can be interpreted not only to analyze the development of the industrial sector, but also other sectors of the country's economy. At the same time, the uniformity of the results provides an opportunity to apply them for analyzing the development of innovation activities of most of the constituent entities of the Russian Federation, determining the list of key problems that impede the more effective implementation of existing innovations, reduce barriers to their implementation, and enhance the level of development of the territory in general.

\section{Conclusion}

The results presented in the research paper include:

- justification of the central place of the consumer in the implementation of the innovation strategy of the region due to the formation of requests to the industrial sector;

- a mechanism for the development of the industrial sector of the region has been formed, which reflects the peculiarities of the "request" of consumers for goods with specific properties, as well as the place of regional authorities in the system for implementing the territory's innovative strategy;

- a model of project financing of the innovation sector of the industrial sector has been developed, distinguished by a systemic vision of the process approach to the practical implementation of innovation through the mapping of the project, resource and time components of the system; 
- a system of mathematical interpretation of a model for the implementation of project financing has been developed, which allows identifying possible barriers to the implementation of specific investment projects at early stages of practical application and envisaging the possibility of lowering their threshold level, which ultimately creates conditions for saving costs at all stages of the innovation process.

\section{References}

1. http://www.garant.ru/products/ipo/prime/doc/70006124/\#ixzz3KNFsMLr4 (Last accessed 11.02.2019)

2. V. Klimova, L. Winklerova, 20th international colloquium on regional sciences, 246-254 (2017) doi : 10.5817/CZ.MUNI.P210-8587-2017-31

3. D. Radushinsky, A. Mottaeva, L. Andreeva, G. Dyakova, IOP Conf. Series: Earth and Environmental Science, 90, 012137 (2017) doi :10.1088/1755$1315 / 90 / 1 / 012218$

4. V. V. Zozulya, L. I. Goncharenko, A. V. Zuikov, G. N. Semenova, Journal of Advanced Research in Law and Economics, 8(5) (2017)

5. A. Mottaeva, MATEC Web of Conferences, 106, 08072 (2017) DOI: 10.1051/matecconf/201710608072

6. T. Kosintseva, et al., Espacios, 38(56), 25, (2017)

7. T. Tereshkina, A. Mottaeva, L. Andreeva, T. Larinina, IOP Conf. Series: Earth and Environmental Science, 90, 012138 (2017) doi:10.1088/1755-1315/90/1/012138

8. P. Zakharov; K. Nazvanova, A. Posazhennikov, Lecture Notes in Networks and Systems, 57, 1155-1168 (2018) doi: 10.1007/978-3-030-00102-5_122

9. S. Grachev, M. Gundorova, O. Donichev, et al. Advances in Intelligent Systems and Computing, 622, 719-726 (2018). doi: 10.1007/978-3-319-75383-6_92

10. O. Goykher, R. Skuba, O. Bugrova, et al., Lecture Notes in Networks and Systems, 57, 1145-1154 (2018) doi: 10.1007/978-3-030-00102-5_121

11. O. Goycher, R. Skuba, O. Bugrova, et al., Advances in Intelligent Systems and Computing, 60, 710-718 (2018). doi: 10.1007/978-3-319-75383-6_91

12. O. Goiher, O. Bugrova, 2nd International Scientific conference on New Industrialization: Global, national, regional dimension (SICNI 2018), Part of series: Advances in Social Science, Education and Humanities Research, doi: https://doi.org/10.2991/sicni-18.2019.140

13. I. Dezhina, Public Administration Issues, 5, 7-26 (2017) doi: 10.17323/19995431-2017-0-5-7-26

14. A. Mottaeva. A. Minullina IOP Conf. Series: Earth and Environmental Science, 90, 012123 (2017) doi :10.1088/1755-1315/90/1/012120

15. O. Donichev, D. Fraimovich, S. Grachev, Economic and social changes-facts trends forecast, 11, 84-99 (2018). doi: 10.15838/esc.2018.3.57.6 